\title{
Cutting Balloon Angioplasty for Carotid Artery In-stent Stenosis Supported by Three-dimensional Rotational Angiography With Automated Vessel Analysis Software
}

\author{
-Technical Note-
}

\author{
Yasuhiko AKIYAMA, Kouzo MORITAKE, Takeshi MIYAZAKI, \\ Kentaro KOWARI, Hidetoshi SATO*, and Toshio SHIMADA* \\ Department of Neurosurgery and *Division of Cardiovascular Medicine, \\ Department of Internal Medicine, Shimane University \\ Faculty of Medicine, Izumo, Shimane
}

\begin{abstract}
In-stent stenosis is a possible long-term complication of carotid artery stenting. A simple and safe technique of cutting balloon angioplasty is described for carotid in-stent stenosis. The stented vessel is imaged by three-dimensional (3D) rotational angiography, the acquired projection images are transferred to a workstation, and the stenotic lesion and implanted stent are reconstructed. The diameter of the implanted stent in the stenotic region is measured by automated analysis software. Cutting balloon angioplasty carries the risk of vessel injury by the cutting balloon microblades, but the implanted stent acts as a barrier to protect the vessel. Therefore, cutting balloon inflation up to the stent diameter is safe and results in maximal vessel dilation. The key to success is precise measurement of the stent diameter and choice of a cutting balloon catheter of the appropriate size. 3D rotational angiography provides high-quality images of the vasculature of a stented vessel and a reference for intervention based on absolute measurements. Cutting balloon angioplasty supported by 3D rotational angiography with automated vessel analysis software should be considered as a treatment strategy for high-grade carotid artery in-stent stenosis.
\end{abstract}

Key words: cutting balloon angioplasty, carotid artery stenting, in-stent stenosis, three-dimensional rotational angiography, automated vessel analysis tool

\section{Introduction}

Carotid artery stenting (CAS) has been evolving as an alternative treatment to carotid endarterectomy for atherosclerotic stenosis, and has achieved favorable short- and medium-term outcomes, especially in surgically high-risk patients. ${ }^{7,11)}$ In-stent stenosis is a possible long-term complication of CAS, but has a low incidence. In-stent stenosis can be treated with open surgical repair. ${ }^{2,5,6)}$ However, endovascular treatment by balloon angioplasty or balloon angioplasty with supplementary stenting is generally performed. Accumulated experience in interventional cardiology suggests that angioplasty with a cutting balloon provides a better initial result and lower recurrence of stenosis than conventional balloon angioplasty for coronary artery in-stent ste-

Received July 4, 2007; Accepted January 11, 2008 nosis. ${ }^{3)}$ The catheter is not a widely used device for neuroendovascular intervention, and there are only a few reports of cutting balloon angioplasty for the treatment of carotid artery in-stent stenosis.,10,12) Furthermore, the technical details essential to achieve successful treatment were not described.

Here we describe the use of cutting balloon angioplasty supported by three-dimensional (3D) rotational angiography with automated vessel analysis software as a straightforward and safe technique for achieving maximal vessel lumen dilation in cases of carotid artery in-stent stenosis.

\section{Surgical Technique}

The patients are given clopidogrel $(75 \mathrm{mg})$ and aspirin $(100 \mathrm{mg}) 1$ week before the treatment. The treatment procedure is performed under local anesthesia. A guide catheter with a size suitable for the cut- 


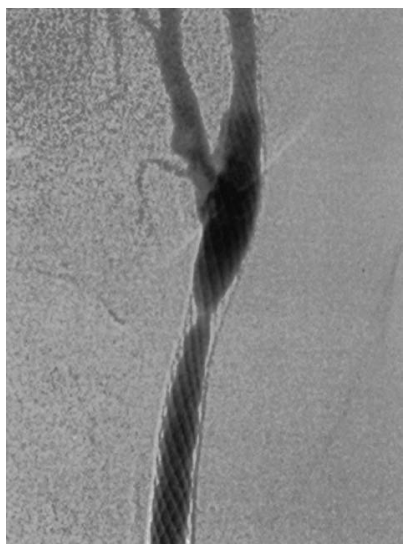

Fig. 1 Two-dimensional digital subtraction angiogram demonstrating in-stent stenosis.

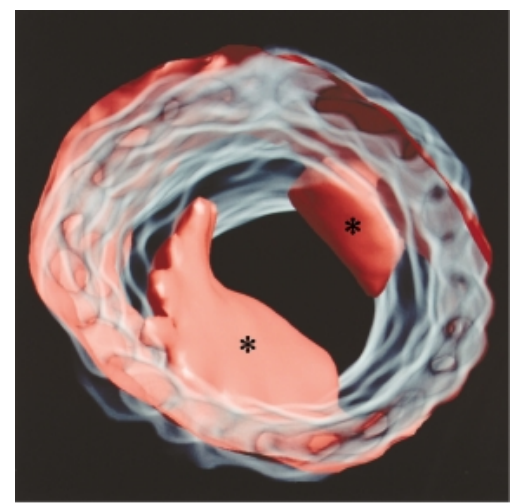

Fig. 2 Post processing of the three-dimensional reconstructed angiogram demonstrating the stent and intimal hyperplasia expanding into the vessel lumen (asterisks).

ting balloon catheter is placed at the proximal portion of the stented segment of the carotid artery. Systemic heparinization is then initiated with intermittent bolus administrations to maintain an activated clotting time of 250 to 300 seconds. Both twodimensional (2D) (Fig. 1) and 3D angiographies are performed using the 3D rotational angiography system (Integris Allura; Philips Electronics Japan, Ltd. Medical Systems, Tokyo). The 3D images display the implanted stent and intimal hyperplasia expanding into the vessel lumen (Fig. 2). The acquired projection images are transferred to a workstation and both the length of the stenotic region and the diameter of the implanted stent in the stenotic region are measured using automated vessel analysis software (Philips Electronics Japan, Ltd. Medical Systems) (Fig. 3).

A cutting balloon catheter expanding up to the di-

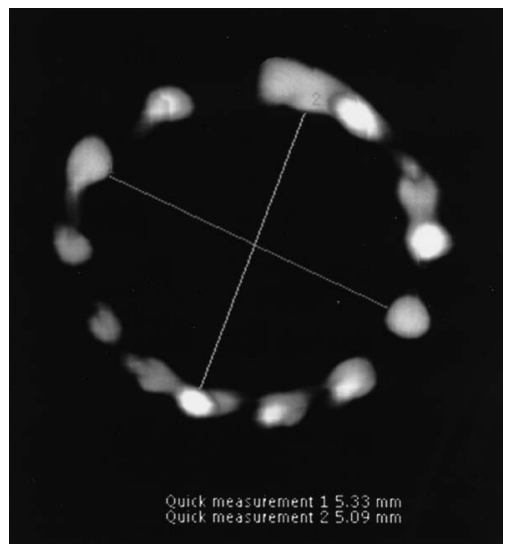

Fig. 3 Axial section of the three-dimensional rotational angiography reconstruction image showing the implanted stent in the region of the in-stent stenosis, and the stent diameter measured by automated vessel analysis software.

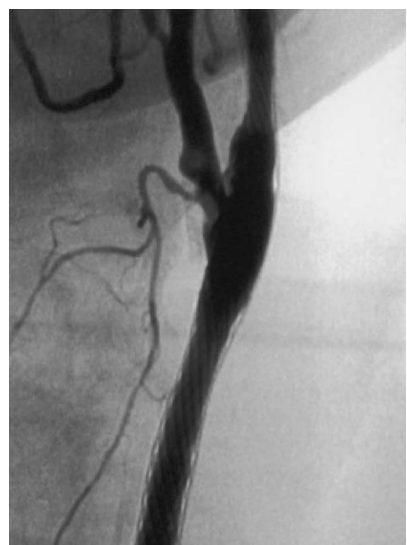

Fig. 4 Two-dimensional digital subtraction angiogram showing the in-stent stenosis resolved by cutting balloon angioplasty.

ameter of the stent at a nominal pressure compared to rated burst pressure is chosen Barath $^{\mathrm{TM}}$ PTCA Balloon Catheter for a vessel diameter below 4 $\mathrm{mm} /$ Peripheral Cutting Balloon ${ }^{\mathrm{TM}}$ for a vessel diameter over $4 \mathrm{~mm}$; Boston Scientific, Fremont, Calif., U.S.A.). Precise measurement of the stent diameter and selection of a cutting balloon catheter of appropriate size are the keys to ensuring successful treatment. Cerebral protection with a Percusurg Guardwire $^{\mathrm{TM}}$ System (Medtronic, Minneapolis, Minn., U.S.A.) is initiated. Then the optimal cutting balloon catheter is deployed at the center of the target lesion and slowly inflated, with a 1-atm pressure increase every 5 seconds, up to the stent diameter, and is retained for 30 seconds. Over-inflation be- 
yond the stent diameter will induce additional stent expansion with the risk of arterial wall dissection. The cutting balloon catheter is deflated and debris is removed. The cutting balloon is withdrawn under continuous negative pressure to prevent the cutting balloon microblades from damaging the guide catheter. This procedure for cutting balloon angioplasty is straightforward and safe for the treatment of carotid artery in-stent stenosis (Fig. 4).

\section{Discussion}

Studies of stents in peripheral and coronary arteries have suggested that in-stent stenosis is caused by myointimal hyperplasia with smooth muscle cell proliferation. The incidence of high-grade severe instent stenosis ( $>80 \%$ ) that warrants treatment is approximately $5 \%$ during 1.5 years of follow up. ${ }^{8,9,12)}$ The optimal management strategy for high-grade instent stenosis has not been established, although repeat endovascular intervention is considered preferable to open surgical repair. ${ }^{9)}$

Cutting balloon angioplasty is a novel neuroendovascular approach. The cutting balloon has 4 sharp microblades mounted longitudinally on the surface of the noncompliant balloon. The cutting balloon is not suitable for highly tortuous lesions because the microblades on the balloon remain straight. However, the device was originally developed for coronary intervention and has excellent trackability and crossability to access stenotic vessels. The mechanism of vessel dilation by cutting balloon angioplasty involves slicing of the neointimal tissue into small segments by the microblades, and extrusion of the fragmented intimal tissue out of the stent through the stent struts by the noncompliant balloon, with very little additional stent expansion. ${ }^{1)}$ In-stent stenosis of more than $75 \%$ vessel diameter loss in the coronary artery generally indicates treatment, and such high-grade restenosis occurs in $20-80 \%$ of all percutaneous transluminal coronary angioplasty. ${ }^{3)}$ Cutting balloon angioplasty yields larger initial gain and lower recurrence of stenosis for coronary artery. ${ }^{3)}$

We propose that precise measurement of the stent diameter as a reference for intervention and choice of the appropriate size of the cutting balloon catheter are the keys to success for cutting balloon angioplasty. Although cutting balloon angioplasty carries the risk of vessel injury by the microblades, the implanted stent acts as a barrier to protect the vessel from the microblades in cases of in-stent stenosis. Therefore, maximal cutting balloon inflation up to the stent diameter is safe and results in maximal vessel dilation. A number of imaging modalities are available for visualization and measurement of the vessel and stent, including computed tomography angiography, intravascular ultrasonography, 2D digital subtraction angiography, and 3D rotational angiography. Although no gold standard has been established, 3D rotational angiography provides high-quality images of the vasculature as well as the implanted stent without substantial prolongation of the procedure time, and automatically provides a reference for intervention based on absolute measurements obtained with automated analysis software. We successfully treated two cases of instent stenosis after CAS with the present cutting balloon angioplasty technique.

Cutting balloon angioplasty supported by 3D rotational angiography with automated vessel analysis software is simple and safe, and enables maximal vessel lumen dilation. Further investigations of cutting balloon angioplasty for carotid artery in-stent stenosis are required to confirm its clinical efficacy and long-term outcomes, but this technique should be considered as a potential treatment strategy for high-grade carotid artery in-stent stenosis.

\section{References}

1) Ahmed JM, Mintz GS, Castagna M, Weissman NJ, Pichared AD, Satler LF, Kent KM: Intravascular ultrasound assessment of the mechanism of lumen enlargement during cutting balloon angioplasty treatment of in-stent restenosis. Am J Cardiol 88: 10321034, 2001

2) Akin E, Knobloch K, Pichlmaier M, Haverich A: Instent restenosis after carotid stenting necessitating open carotid surgical repair. Eur J Cardiothorac Surg 26: 442-443, 2004

3) Auer J, Maurer E, Berent R, Mayr H, Punzengruber C, Weber T, Lassnig E, Eber B: Clinical and angiographic outcomes after cutting balloon angioplasty. J Interv Cardiol 16: 15-21, 2003

4) Bendok BR, Roubin GS, Katzen BT, Boulos AS, Levy EI, Limpijankit T, Qureshi AI, Guterman LR, Hopkins LN: Cutting balloon to treat carotid in-stent stenosis: technical note. J Invasive Cardiol 15: 227-232, 2003

5) Brown KR, Desai TR, Schwartz LB, Gewertz BL: Operative intervention for recurrent stenosis after carotid stent angioplasty: a report. Ann Vasc Surg 16: 575-578, 2002

6) de Borst GJ, Ackerstaff RG, Mauser HW, Moll FL: Operative management of carotid artery in-stent restenosis: first experience and duplex follow-up. Eur J Vasc Endovasc Surg 26: 137-140, 2003

7) Gray WA, Hopkins LN, Yadav S, Davis T, Wholey M, Atkinson R, Cremonesi A, Fairman R, Walker G, Verta P, Popma J, Virmani R, Cohen DJ; ARCHeR Trial Collaborators: Protected carotid stenting in high-sur- 
gical-risk patients: the ARCHeR results. J Vasc Surg 44: 258-268, 2006

8) Levy EI, Hanel RA, Lau T, Koebbe CJ, Levy N, Padalino DJ, Malicki KM, Guterman LR, Hopkins LN: Frequency and management of recurrent stenosis after carotid artery stent implantation. J Neurosurg 102: 29-37, 2005

9) Setacci C, de Donato G, Setacci F, Pieraccini M, Cappeli A, Trovato RA, Benevento D: In-stent restenosis after carotid angioplasty and stenting: a challenge for the vascular surgeon. Eur J Vasc Endovasc Surg 29: 601-607, 2005

10) Tamberella MR, Yadav JS, Bajzer CT, Bhatt DL, Abou-Chebl A: Cutting balloon angioplasty to treat carotid in-stent restenosis. J Invasive Cardiol 16: 133-135, 2004

11) Yadav JS, Wholey MH, Kuntz RE, Fayad P, Katzen BT, Mishkel GJ, Bajwa TK, Whitlow P, Strickman NE, Jaff MR, Popma JJ, Snead DB, Cutlip DE, Firth BG, Ouriel K; Stenting and Angioplasty with Protection in Patients at High Risk for Endarterectomy Investigators: Protected carotid-artery stenting versus endarterectomy in high-risk patients. $N$ Engl J Med 351: 1493-1501, 2004

12) Zhou W, Lin PH, Bush RL, Peden EK, Guerrero MA, Kougias P, Lumsden AB: Management of in-stent restenosis after carotid artery stenting in high-risk patients. J Vasc Surg 43: 305-312, 2006
Address reprint requests to: Yasuhiko Akiyama, M.D., Department of Neurosurgery, Shimane University School of Medicine, 89-1 Enya-cho, Izumo, Shimane 693-8501, Japan.

e-mail: yakiyama@med.shimane-u.ac.jp

\section{Commentary}

Akiyama et al. have documented that favorable outcomes were achieved in patients with high-grade carotid artery in-stent stenosis using cutting balloon angioplasty supported by three-dimensional rotational angioplasty. Their focus is that the implanted stent acts as a barrier to protect the vessel from the injury by the cutting balloon microblades. They also showed that precise measurement of the stent diameter as a reference for intervention and choice of the appropriate size of the cutting balloon catheter were the keys to success for this approach. I think the combination of these techniques may expand the treatment strategy for high-grade carotid artery in-stent stenosis. I look forward to the next report of a larger number of cases with this approach.

Jun-ichiro HAMADA, M.D.

Department of Neurosurgery

Graduate School of Medical Science

Kanazawa University

Kanazawa, Japan 